\title{
Maternal parameters in lower segment caesarean section: a comparative study of the effects of spinal anaesthetic agents
}

\author{
M. Paul Wilson ${ }^{1}$, Usha Christopher ${ }^{2}$
}

\begin{abstract}
${ }^{1}$ Department of Anaesthesiology, ${ }^{2}$ Department of Obstetrics and Gynaecology, Dr. Somervell Memorial CSI Medical College and Hospital, Karakonam 695504, Kerala, India
\end{abstract}

Received: 16 October 2016

Accepted: 21 October 2016

\section{*Correspondence:}

Dr. M. Paul Wilson,

E-mail: paulwilson555@gmail.com

Copyright: () the author(s), publisher and licensee Medip Academy. This is an open-access article distributed under the terms of the Creative Commons Attribution Non-Commercial License, which permits unrestricted non-commercial use, distribution, and reproduction in any medium, provided the original work is properly cited.

\section{ABSTRACT}

Background: With bupivacaine, intrathecal opioids are widely used in spinal anaesthesia for LSCS. We wanted to study the effects of intrathecal opioids on maternal parameters.

Methods: With 20 patients in each group, the study was done in 40 patients posted for LSCS. One group received only bupivacaine and another group received intrathecal fentanyl and bupivacaine. Maternal parameters related to sensory block, motor block and analgesia were recorded.

Results: Intrathecal fentanyl prolonged analgesia and reduced the duration of motor blockade.

Conclusions: Fentanyl is a good adjuvant for intrathecal bupivacaine in LSCS.

Keywords: Analgesia duration, Intrathecal fentanyl, LSCS, Motor blockade

\section{INTRODUCTION}

Caesarean section is the very common emergency surgery in obstetrics. ${ }^{1}$ When the patients come for emergency lower segment caesarean section (LSCS), the obstetrician and the anaesthetist are in their toes because of the challenging situation. Regional anaesthesia is the preferred anaesthetic technique for LSCS. ${ }^{2}$ Regional anaesthesia can be spinal anaesthesia, epidural anaesthesia or combined spinal epidural anaesthesia. Among these, spinal anaesthesia is the highly preferred regional anaesthesia. Spinal anaesthesia is a common anaesthesia in obstetrics. ${ }^{3}$ Quick anaesthesia can be achieved by spinal anaesthesia. Spinal anaesthesia provides reliable intraoperative anaesthesia and good quality postoperative analgesia. ${ }^{4}$

In LSCS regional anaesthesia is preferred than general anaesthesia. ${ }^{5}$ General anaesthesia has lot of maternal and foetal risks. Several drugs are used during general anaesthesia. These drugs can enter the placental circulation and act on the foetus. In general anaesthesia, mother may aspirate gastric contents into the lungs which can result in chemical pneumonitis.

In regional anaesthesia since the mother is awake, she can start nursing the baby early. Regional anaesthesia is easy to administer than general anaesthesia. Regional anaesthesia continues analgesia to the postoperative period also.

Several adjuvants have been tried for several years to be administered along with intrathecal injection of local anaesthetic agents. The purpose of adjuvants is to reduce the volume of local anaesthetic agents and thus to minimise the adverse effects of large volume of local anaesthetic agents. ${ }^{6}$ The adjuvants prolong the duration of analgesia but they shorten the duration of motor blockade. So early recovery from motor blockade after the surgery is facilitaed by adjuvants. In LSCS intrathecal fentanyl reduces the volume of bupivacaine. ${ }^{7}$ Intrathecal fentanyl improves the intensity and quality of spinal 
anaesthesia. Intrathecal fentanyl reduces the time to establish sensory block. With bupivacaine, intrathecal opioids are widely used in spinal anaesthesia for LSCS. ${ }^{8}$

The combined effect of fentanyl and local anaesthetic agent results in prolonged analgesia. Intrathecal opioids increased the duration of postoperative analgesia. There is much more prolongation of analgesia but without compromising the completeness or effectiveness of the analgesia. ${ }^{9}$ Intrathecal opioids increase the duration of spinal anesthesia but at the same time minimise the adverse effects to a significant level.

Intrathecal administration of fentanyl can cause pruritus, nausea, vomiting and respiratory depression which is not desirable in pregnant patients. ${ }^{10} \mathrm{We}$ could not observe any such adverse effects of intrathecal fentanyl on the neonates or the mothers in our study.

\section{METHODS}

The aim of the study was to compare the maternal parameters during Lower Segment Caesarean Section produced by hyperbaric bupivacaine $0.5 \% 1.8 \mathrm{ml}$ alone with a mixture of hyperbaric bupivacaine $0.5 \% 1.6 \mathrm{ml}$ and fentanyl $10 \mu \mathrm{g}(0.2 \mathrm{ml})$.

The following parameters were studied in each group.

1. Highest level of sensory blockade

2. Time to achieve the highest level of sensory blockade

3. Initial grade of motor blockade

4. Level of sensory blockade at the end of surgery

5. Duration of complete analgesia

6. Grade of motor blockade at the end of and after surgery.

\section{Design}

Ethical committee approval and clearance was obtained. Following ethical committee approval, patients were thoroughly explained regarding the nature of study. A written informed consent was obtained from all the patients. Patients were randomized with the help of a computer generated random table.

\section{Selection criteria}

- Women scheduled for Caesarean section

- $\quad$ ASA Grade I

- $\quad$ ASA Grade II

- Height more than $140 \mathrm{cms}$

- 20-35 years age

Exclusion criteria

- Multiple pregnancies

- Bleeding diathesis

- COPD
- Heart diseases

- Hypertensive disorders

- $\quad$ Acute foetal distress

Fentanyl causes respiratory depression. Hence the antenatal patients with acute foetal distress were excluded from the study.

As soon as the patient reaches the operating room, an intravenous cannula $(16 \mathrm{G}$ or $18 \mathrm{G}$ ) was inserted into a wide and straight vein in the forehand. Patients were preloaded with intravenous Ringer lactate solution at a volume of $20 \mathrm{ml} / \mathrm{kg}$. Pulse rate, blood pressure and respiratory rate were recorded before spinal anaesthesia. Lumbar puncture was performed under all aseptic precautions with 25 gauge Quincke's needle in the L3-L4 space in the left lateral position after local infiltration with $2 \%$ plain lignocaine. According to random assignment, the drugs were injected as per the group of the patient. Patient was immediately placed in supine position. Under the right hip a wedge was placed. All patients received supplementation of $\mathrm{O}_{2}(5$ litres per minute) using Hudson's mask.

After the administration of spinal anaesthesia, heart rate, blood pressure and rate of respiration were recorded every 2 minutes for first 30 minutes. Then vital signs were recorded at 5 minutes interval for remaining period of the surgery. Thereafter vital signs were recorded at 30 minutes interval until the patient complained of pain. $\mathrm{SpO}_{2}$ was monitored continuously. The onset and duration of sensory block was assessed. Time taken from subarachnoid injection to the highest level of sensory block was recorded. The onset and duration of sensory block was assessed with the help of pinprick method. The duration of complete analgesia was recorded. It is the time from subarachnoid injection to the time when patient complains of pain.

The onset of motor block was noted. The duration of motor block was noted. Grading of motor block was done with Bromhage scale.

$0=$ No paralysis

$1=$ Inability to raise extended leg

2 = Inability to flex the knee

$3=$ Inability to flex the ankle (complete motor block)

Apgar scores were recorded at 1 minute and 5 minutes after delivery of baby.

If the systolic blood pressure fell below $90 \mathrm{~mm} \mathrm{Hg}$, incremental doses of intravenous ephedrine were given to maintain systolic blood pressure above $90 \mathrm{~mm} \mathrm{Hg}$. If bradycardia occured intravenous atropine $0.6 \mathrm{mg}$ was given. 


\section{Sample size}

Totally forty women of ASA I and ASA II scheduled for Caesarean section were selected for this study. They were divided into two groups with twenty patients in each group.

\section{Methodology}

Forty women of ASA I and ASA II scheduled for Caesarean section were selected for this study. Patients were randomly allocated to receive either $1.8 \mathrm{ml}$ of $0.5 \%$ hyperbaric bupivacaine hydrochloride (Group A, n= 20) or $1.6 \mathrm{ml}$ of $0.5 \%$ hyperbaric bupivacaine hydrochloride with $0.2 \mathrm{ml}(10 \mathrm{ug})$ fentanyl citrate (using a tuberculin syringe) (Group $\mathrm{B}, \mathrm{n}=20$ ). All the study drugs were introduced intrathecally. The total volume administered was $1.8 \mathrm{ml}$

\section{Statistical analysis}

Data were analysed using unpaired ' $t$ ' test. $P$ value $\leq 0.05$ was considered statistically significant. Data is presented as mean values $\pm \mathrm{SD}$ and numbers (percent).

\section{RESULTS}

\section{Demographic data analysis}

The comparability of the two groups was tested by t- test, with respect to the age.

Table 1: t-Test for age.

\begin{tabular}{lllllll} 
Parameter & Group & N & Mean & Std deviation & Std error mean & p - value \\
\multirow{2}{*}{ Age } & A (Bupivacaine) & 20 & 26.45 & 2.982 & 0.667 & 0.138 \\
\cline { 2 - 5 } & B (Bupivacaine + Fentanyl) & 20 & 25.15 & 2.412 & 0.539 & 0.139 \\
\hline
\end{tabular}

Table 2: t-Test for height.

\begin{tabular}{lllllll} 
Parameter & Group & N & Mean & Std deviation & Std error mean & p - value \\
\multirow{2}{*}{ Height } & A (Bupivacaine) & 20 & 151.70 & 3.895 & 0.871 & 0.821 \\
\cline { 2 - 6 } & B (Bupivacaine + Fentanyl) & 20 & 152.05 & 5.652 & 1.264 & 0 \\
\hline
\end{tabular}

Table 3: t-Test for weight.

\begin{tabular}{|lllllll|}
\hline Parameter & Group & N & Mean & Std deviation & Std error mean & p - value \\
\multirow{2}{*}{ Weight } & A (Bupivacaine) & 20 & 62.70 & 6.921 & 1.548 & 0.697 \\
\cline { 2 - 5 } & B (Bupivacaine + Fentanyl) & 20 & 61.65 & 9.778 & 2.186 & 0.69 \\
\hline
\end{tabular}

Since the $\mathrm{p}$ - value is greater than 0.05 , the difference in the age between the two groups is statistically not significant. Hence the data of both groups can be compared with respect to the age.

The comparability of the two groups was tested by t- test, with respect to the height.

Since the $\mathrm{p}$ - value is greater than 0.05 , the difference in the height between the two groups is statistically not significant. Hence the data of both groups can be compared with respect to the height.

The comparability of the two groups was tested by t- test, with respect to the weight.

Since the p- value is greater than 0.05 , the difference in the weight between the two groups is statistically not significant. Hence the data of both groups can be compared with respect to the weight.
The highest level of sensory block was recorded for both groups.

Table 4: Highest level of sensory block.

\begin{tabular}{|llll|}
\hline \multirow{2}{*}{ Group } & \multicolumn{3}{l|}{ Patients with highest } \\
& level of sensory & blockade \\
\hline A (Bupivacaine) & T2 & T4 & T6 \\
\hline B (Bupivacaine+Fentanyl) & 0 & 18 & 2 \\
\hline Total & 6 & 14 & 0 \\
\hline
\end{tabular}

The highest level of sensory blockade was T4 dermatome in $18(90 \%)$ patients of group A and $14(70 \%)$ patients of group B. In group B, $6(30 \%)$ patients got highest sensory level as T2 dermatome, whereas $2(10 \%)$ patients in group A got highest sensory level as T6 dermatome.

The time taken to achieve the highest level of sensory blockade was noted for both groups. 
Table 5: Time for achieving highest level of sensory block.

\begin{tabular}{|c|c|c|c|c|}
\hline \multirow{2}{*}{$\begin{array}{l}\text { Parameter } \\
\text { Time to achieve highest level } \\
\text { (Minutes) }\end{array}$} & \multirow[b]{2}{*}{ Magnitude } & \multicolumn{2}{|l|}{ Group } & \multirow[b]{2}{*}{ Total } \\
\hline & & A (Bupivacaine) & B (Bupivacaine + Fentanyl) & \\
\hline \multirow[b]{2}{*}{2} & Number of patients & 0 & 6 & 6 \\
\hline & $\%$ within group & $0 \%$ & $30.0 \%$ & $15 \%$ \\
\hline \multirow{2}{*}{2.5} & Number of patients & 0 & 3 & 3 \\
\hline & $\%$ within group & $0 \%$ & $15 \%$ & $7.5 \%$ \\
\hline \multirow{2}{*}{3} & Number of patients & 1 & 11 & 12 \\
\hline & $\%$ within group & $5.0 \%$ & $55 \%$ & $30 \%$ \\
\hline \multirow{2}{*}{3.5} & Number of patients & 3 & 0 & 3 \\
\hline & $\%$ within group & $15 \%$ & $0 \%$ & $7.5 \%$ \\
\hline \multirow{2}{*}{4} & Number of patients & 15 & 0 & 15 \\
\hline & $\%$ within group & $75 \%$ & $0 \%$ & $37.5 \%$ \\
\hline \multirow{2}{*}{4.5} & Number of patients & 1 & 0 & 1 \\
\hline & $\%$ within group & $5.0 \%$ & $0 \%$ & $2.5 \%$ \\
\hline Total & & 20 & 20 & 40 \\
\hline
\end{tabular}

Table 6: t-Test for duration of analgesia.

\begin{tabular}{|lllllll|}
\hline Parameter & Group & N & Mean & Std deviation & Std error mean & p - value \\
\hline $\begin{array}{l}\text { Duration of } \\
\text { analgesia (Minutes) }\end{array}$ & A (Bupivacaine) & 20 & 137.2500 & 7.34041 & 1.64136 & 0.000 \\
\cline { 2 - 7 } & B (Bupivacaine + Fentanyl) & 20 & 181.2500 & 17.61242 & 3.93826 & 0.00 \\
\hline
\end{tabular}

Mean time to reach the highest level of sensory blockade was 3.9 minutes in group A and 2.62 minutes in group B.

One (5\%) patient in group A achieved highest level of sensory blockade in 3 minutes, 3 patients were able to reach highest level in 3.5 minutes, 15 patients in 4 minutes and one patient in 4.5 minutes.

In group B, $6(30 \%)$ patients got highest sensory level in 2 minutes, 3 patients were able to reach highest level in 2.5 minutes and $11(55 \%)$ patients in 3 minutes.

The duration of analgesia was recorded in both groups.

The mean duration of analgesia in group A was 137.25 minutes, whereas in group B it was 181.25 minutes. Values were analyzed using unpaired t-test and found to have a p - value of 0.000 which is statistically significant. So group B has longer duration of analgesia as compared to group A.

Table 7: Mann-Whitney test for duration of analgesia.

\begin{tabular}{|lllll|}
\hline Test Statistics & Grouping & Groups & N & $\begin{array}{l}\text { p - } \\
\text { vaue }\end{array}$ \\
\hline $\begin{array}{l}\text { varameter } \\
\text { varation of } \\
\text { analgesia } \\
\text { (Minutes) }\end{array}$ & Drug & A (Bupivacaine) & 20 & \\
\cline { 2 - 4 } & $\begin{array}{l}\text { B (Bupivacaine } \\
\text { + Fentanyl) }\end{array}$ & 20 & 0.000 \\
\hline
\end{tabular}

The data was further analyzed using Mann-Whitney Test and found to have a p - value 0.000 which is statistically significant. Thus group B has longer duration of analgesia as compared to group A.

Grading of motor block was done as per Bromhage scale

$0=$ No paralysis

$1=$ Inability to raise extended leg

2 = Inability to flex the knee

$3=$ Inability to flex the ankle (complete motor block)

Complete motor block was noted in all the patients at the time of incision, in our study. All the patients maintain complete motor block throughout the surgery. Level of motor blockade was again assessed at 1 hour 30 minutes in the recovery room using Bromhage scale. In Group A, 2 (10\%) patients had motor blockade of grade 2 . Remaining 18 (90\%) patients had grade 3 (full) motor blockades at 1 hour 30 minutes. In Group B, 2 (10\%) patients had motor blockade grade 0 , nine (45.0\%) patients had grade 1 , eight $(40.0 \%)$ patients had grade 2 and only $1(5.0 \%)$ patient had grade3 (full) motor blockade at 1 hour 30 minutes. Thus after the surgery, early recovery from the motor blockade could be noted in the Group B. 
Table 8: Grading of motor blockade (From the time of subarachnoid injection).

\begin{tabular}{|c|c|c|c|}
\hline $\begin{array}{l}\text { Time of } \\
\text { assessment }\end{array}$ & Parameter & $\begin{array}{l}\text { A } \\
\text { (Bupivacaine) }\end{array}$ & $\begin{array}{l}\text { B (Bupivacaine } \\
+ \text { Fentanyl) }\end{array}$ \\
\hline \multirow{4}{*}{5 Minutes } & $\begin{array}{l}\text { Bromhage } \\
\text { scale } 0\end{array}$ & 0 & 0 \\
\hline & $\begin{array}{l}\text { Bromhage } \\
\text { scale 1 }\end{array}$ & 0 & 0 \\
\hline & $\begin{array}{l}\text { Bromhage } \\
\text { scale } 2\end{array}$ & 0 & 0 \\
\hline & $\begin{array}{l}\text { Bromhage } \\
\text { scale } 3\end{array}$ & 20 & 20 \\
\hline \multirow{4}{*}{45 Minutes } & $\begin{array}{l}\text { Bromhage } \\
\text { scale } 0\end{array}$ & 0 & 0 \\
\hline & $\begin{array}{l}\text { Bromhage } \\
\text { scale 1 }\end{array}$ & 0 & 0 \\
\hline & $\begin{array}{l}\text { Bromhage } \\
\text { scale } 2\end{array}$ & 0 & 0 \\
\hline & $\begin{array}{l}\text { Bromhage } \\
\text { scale } 3\end{array}$ & 20 & 20 \\
\hline \multirow{4}{*}{$\begin{array}{l}1 \text { hour } \\
30 \text { Minutes }\end{array}$} & $\begin{array}{l}\text { Bromhage } \\
\text { scale } 0\end{array}$ & 0 & 2 \\
\hline & $\begin{array}{l}\text { Bromhage } \\
\text { scale 1 }\end{array}$ & 0 & 9 \\
\hline & $\begin{array}{l}\text { Bromhage } \\
\text { scale } 2\end{array}$ & 2 & 8 \\
\hline & $\begin{array}{l}\text { Bromhage } \\
\text { scale } 3\end{array}$ & 18 & 1 \\
\hline
\end{tabular}

\section{DISCUSSION}

Recent trends in obstetric anaesthesia show high popularity of spinal anaesthesia amongst obstetric anaesthetists. General anaesthesia is associated with higher mortality rate when comparing to regional anaesthesia. ${ }^{11}$ Spinal anaesthesia, a simple reliable technique has rapid onset, provides an awake and comfortable patient with minimal risks for pulmonary aspiration of gastric contents.

Regional anesthesia also has some risk. Despite the lower abdominal incision, a T4 sensory dermatome level is required to prevent referred pain from traction on the peritoneum and uterus. ${ }^{12}$ The type and dose of local anesthetic should be chosen so as to have adequate level and duration of analgesia. The almost immediate onset of action of fentanyl reduces visceral discomfort. By the addition of opioids, there is a reduction in the dose of local anaesthetic drug. This leads to a decrease in the toxicity of local anaesthetics. Ultimately there is a reduction in the complications related with regional anaesthesia.

In our study we decided to compare the effects of traditional choice of hyperbaric bupivacaine $(0.5 \%)$ with a mixture of fentanyl and bupivacaine on maternal parameters viz., as level of sensory blockade and duration of complete analgesia.
The two groups were comparable with respect to mean age, weight and height.

The mean age in group A was $26.45 \pm 2.982$ years whereas in group B it was $25.15 \pm 2.412$ years with a p- value of 0.138 which is statistically not significant.

The mean height in group A was $151.70 \pm 3.895 \mathrm{cms}$ whereas in group B it was $152.05 \pm 5.652 \mathrm{cms}$ with a pvalue of 0.821 which is statistically not significant.

The mean weight in group A was $62.70 \pm 6.921 \mathrm{kgs}$ whereas in group B it was $61.65 \pm 9.778 \mathrm{kgs}$ with a p-value of 0.697 which is statistically not significant. Thus the data of two groups were comparable with respect to mean age, weight and height.

In LSCS the desired level of sensory block is T4 dermatome. ${ }^{12}$ This was achieved in all the patients in fentanyl group. In bupivacaine group only 18 patients could get T4 level sensory block. Two patients could get T6 level sensory block only. S Gauchan et al in their study found that all the patients of fentanyl group got a sensory block of T4 dermatome. ${ }^{13}$ Their study was conducted in LSCS spinal anaesthesia patients in which one group received only bupivacaine and another group got fentanyl with bupivacaine.

The mean duration of analgesia in group A was 137.25 minutes, whereas in group B it was 181.25 minutes. The values were analyzed using unpaired t- test and found $\mathrm{p}$ value of 0.000 which is statistically significant. The data were further analyzed using Mann-Whitney test and found to have a p- value 0.000 which is statistically significant. Thus group B has longer duration of analgesia as compared to group A, which is similar with the study of Anupam Chakrabarti et al. ${ }^{14}$ In their study they found that intrathecal fentanyl significantly prolonged the duration of analgesia. They conducted study in LSCS patients after spinal anaesthesia comparing a combination of bupivacaine and fentanyl with bupivacaine alone.

In our study the mean time to achieve highest level of sensory blockade was 3.9 minutes in group A and 2.62 minutes in group B. One $(5 \%)$ patient in group A achieved highest level of sensory blockade in 3 minutes, three patients were able to reach highest level in 3.5 minutes, 15 patients in 4 minutes and one patient in 4.5 minutes. In group B $6(30 \%)$ patients got highest sensory level in 2 minutes, 3 patients were able to reach highest level in 2.5 minutes and $11(55 \%)$ patients in 3 minutes. Thus in our study, addition of fentanyl with bupivacaine accelerated the achievement of highest level of sensory block. Dahlgren et al also noted that fentanyl facilitated the early achievement of highest sensory block. ${ }^{15}$

Complete motor block was achieved in all the patients in our study. Level of motor blockade was again assessed in the recovery room using Bromhage scale. In Group A, 2 
(10\%) patients had motor blockade grade 2 and rest 18 $(90 \%)$ of the patients had grade 3 (full) motor blockade at 1 hour 30 minutes. In Group B, 2 (10\%) patients had motor blockade grade 0 , nine $(45.0 \%)$ patients had grade 1, eight $(40.0 \%)$ patients had grade and only $1(5.0 \%)$ patient had grade 3 (full) motor blockade at 1 hour 30 minutes. Thus after the surgery, early recovery from the motor blockade could be noted in the Group B i.e., fentanyl facilitated early recovery from the motor blockade. Bruce Ben-David et al also had similar findings. ${ }^{16}$

\section{CONCLUSION}

On the basis of our study, we reached the conclusion that addition of fentanyl in bupivacaine prolonged the analgesia and thereby delayed the requirement of systemic analgesic requirement in the immediate post operative period. The recession of the motor blockade is faster with the addition of fentanyl. There was no incidence of respiratory depression, pruritus or vomiting in either of the group. Thus we conclude that bupivacaine $0.5 \% 1.6 \mathrm{ml}$ and fentanyl 10 micrograms provide longer duration of analgesia and adequate motor blockade than bupivacaine alone without additional adverse effects.

\section{ACKNOWLEDGEMENTS}

We are greatly thankful to research department staff, nursing staff, data entry operators and statisticians.

Funding: No funding sources

Conflict of interest: None declared

Ethical approval: The study was approved by the Institutional Ethics Committee

\section{REFERENCES}

1. Robson M, Hartigan L, Murphy M. Methods of achieving and maintaining an appropriate caesarean section rate; Best Practice and Research: Clinical Obstetrics and Gynaecology. 2013;27(2):297-308.

2. Kosam D, Kosam A, Murthy M. Effect of various techniques of Anesthesia in elective Caesarian section on short term Neonatal outcome; Int J of Med Res and Rev. 2014;2(5).

3. Aksoy M, Aksoy AN, Dostbil A, Çelik MG, Ahıskalığlu A. Anaesthesia Techniques for Caesarean Operations: Retrospective Analysis of Last Decade; Turk J Anaesth Reanim. 2014;42:12832.

4. Gizzo S, Noventa M, Fagherazzi S. Update on best available options in obstetrics anaesthesia: perinatal outcomes, side effects and maternal satisfaction.
Fifteen years systematic literature review; Archives of Gyne and Obste: 2014;290(1):21-34.

5. Steven BL, Catherine SY, Steven WJ, Mark LB. Complications of Anesthesia for Cesarean Delivery; Obste and Gyne. 2005;106(2):281-7.

6. Staikou C, Paraskeva A. The effects of intrathecal and systemic adjuvants on subarachnoid block. Minerva Anestesiological. 2014;80(1):96-112.

7. Pöpping DM, Elia N, Wenk M, Tramèr MR. Can the dose of the local anaesthetic for intrathecal anaesthesia is reduced when an opioid is added? A meta-analysis of randomised trials; Eur $\mathrm{J}$ of Anae. 2013;30:130.

8. Wilwerth M, Majcher JL, Van der Linden P. Spinal fentanyl vs. sufentanil for post-operative analgesia after C-section: a double-blinded randomised trial. Acta Anaesthesiologica Scandinavica. 2016;60(9):1306-13.

9. Rathmell JP, Lair TR, Nauman B. The role of intrathecal drugs in the treatment of acute pain. Anesth Analg. 2005;101(5):S30-43.

10. Armstrong S, Fernando R. Side Effects and Efficacy of Neuraxial Opioids in Pregnant Patients at Delivery: A Comprehensive Review. Drug Safety. 2016;39(5):381-99.

11. Rodgers A, Walker N, Schug S, McKee A. Reduction of postoperative mortality and morbidity with epidural or spinal anaesthesia: results from overview of randomised trials. BMJ. 2000;321:1493.

12. Russell IF. A comparison of cold, pinprick and touch for assessing the level of spinal block at caesarean section. 2004;13(3):146-52.

13. Gauchan S, Thapa C, Prasai A, Pyakurel K, Joshi I, Tulachan J. Effects of intrathecal fentanyl as an adjunct to hyperbaric bupivacaine in spinal anesthesia for elective caesarean section. Nepal Med Coll J. 2013;15(3):156-9.

14. Chakrabarti A, Debroy D, Ray J. The Study of Haemodynamics and Neonatal Outcome Following Spinal Anaesthesia with Low Dose Hyperbaric Bupivacaine with and Without Fentanyl in Patients Undergoing Elective Caesarean Section. $\mathrm{J}$ of Res in Anae and Pain Med. 2015;1(1):1-7.

15. Gunnar D, Christer H, Jan J, Mikael N, Eva EW, Helena M. Intrathecal Sufentanil, Fentanyl, or Placebo Added to Bupivacaine for Cesarean Section. Anesthesia and Analgesia: 1997;85(6):1288-93.

16. Ben-David B, Miller G, Gavriel R, Gurevitch A. Low-dose bupivacaine-fentanyl spinal anesthesia for cesarean delivery. Regional Ane and Pain Med. 2000;25(3):235-9.

Cite this article as: Wilson MP, Christopher U. Maternal parameters in lower segment caesarean section: a comparative study of the effects of spinal anaesthetic agents. Int J Reprod Contracept Obstet Gynecol 2016;5:4136-41. 